\title{
MRS International Meeting on Advanced Materials-Tokyo Report
}

The following symposium summaries are part of a continuing series of reports on the MRS International Meeting on Advanced Materials held May 30-June 3, 1988 in Tokyo, Japan. Summaries of symposia $\mathrm{D}, \mathrm{E}, \mathrm{H}, \mathrm{J}, \mathrm{L}, \mathrm{M}, \mathrm{O}$, and $\mathrm{S}$ were published in the October MRS BULLETIN, p. 72. The summaries describe only the highlights of the symposia. Readers interested in detailed technical content can order the symposium proceedings being published by the Materials Research Society.

For an overview of the MRS International Meeting on Advanced Materials, plus several other major materials meetings held in Asia about the same time, see the September MRS BULLETIN, p. 29.

\section{Composites-A}

Organizers: S. Umekawa (Science University of Tokyo), A. Kobayashi (University of Tokyo), and S. Kimura (Tokyo Institute of Technology).

The wealth of knowledge shared in three invited talks and 42 contributed presentations resulted in enthusiastic discussion during this symposium.

W.C. Harrigan focused on the commercial application of metal matrix composites such as discontinuously reinforced composites for engine components and continuous graphite fiber composites for passive heat pipes, zero expansion space structure, and ultralow expansion heat sinks for circuit boards. He noted that the composite nature of the materials contributed distinct and beneficial properties.

The effectiveness of fabricating aluminum matrix composites containing short fibers of $\mathrm{Al}_{2} \mathrm{O}_{3}$ or $\mathrm{SiC}$ by heating slightly above the aluminum melting temperature was examined for high temperature extrusion, hot pressing, and casting. In addition to the effect of small additions of bauxite, $\mathrm{MgAl}_{2} \mathrm{O}_{4}, \mathrm{AlN}, \mathrm{Si}_{3} \mathrm{~N}_{4}, \mathrm{SiC}$, and $\mathrm{SiNi}$ on the improved strength and wear resistance of aluminum matrix composites was described. Special attention was given to the effectiveness of a rapid cooling and rotation technique to improve the ductility of these composites.

Extensive discussion centered on the fracture behavior of $\mathrm{SiC}_{\mathrm{w}} / \mathrm{Al}$ as observed in situ in a scanning electron microscope. Short fibers in an aluminum matrix were observed to increase the fatigue life. Fracture characterization of ceramic/metal composites was extended to elucidate the dependence of metal phase continuity on the transition from ductile to brittle behavior. The effect of crack bridging on crack propagation in the laminate ARALL
(Aramid Reinforced Aluminum Laminate) was described for the case in which the bridging zone was distributed 3-5 $\mathrm{mm}$ behind the crack tip. Fracture toughness of carbon fiber reinforced aluminum and high temperature creep for $\mathrm{Al}_{4} \mathrm{C}_{3} / \mathrm{Al}$ were also analyzed. For the latter case the thermal activation energy measured was reported to be larger than that of aluminum self-diffusion. Another paper analyzed the high temperature strength of carbon fiber/ metal composites using a Monte Carlo simulation based on a shear-lag theory. Variations in strength of the composites were found to depend on the "ineffective length" found near the ends of the fibers.

For ceramic composites D.B. Marshall in his invited talk discussed the fundamental role the interface plays in determining the mechanical properties. Later a diamonddispersed/glass composite fabricated under $10^{4}-10^{5} \mathrm{G}$ of microgravity was described. This material showed no evidence of foam formation. It had a homogeneous distribution of diamond which yielded a fracture toughness of $\mathrm{K}_{\mathrm{rc}}-0.33 \mathrm{MN} / \mathrm{m}^{3 / 2}$. Another paper showed that reinforcement of sintered $\mathrm{Al}_{2} \mathrm{O}_{3}$ with a dispersion of 0.3 $\mu \mathrm{m} \mathrm{SiC} \mathrm{gave} \mathrm{a} \mathrm{high} \mathrm{value} \mathrm{of} \mathrm{K}_{\mathrm{Ic}}-4.7 \mathrm{MN} /$ $\mathrm{m}^{3 / 2}$, and that a similar dispersion of $\mathrm{SiC}_{\mathrm{w}}$ in spinel also improved its toughness. A paper on carbon matrix materials showed that the addition of fine $(\leqslant 1 \mu \mathrm{m})$ graphite powder produced a mosaic microstructure and was associated with the high strength of $910 \mathrm{MPa}$. Another talk demonstrated that both carbon and $\mathrm{SiC}$ fiber reinforcement in carbon increased the fracture toughness and the work of fracture.

Prof. M. Van de Voorde's invited talk dwelled on the future applications of ceramic composites for high temperature use, citing recent examples in the aerospace and automobile industries. For these applications service reliability from long lifetime design is also important. Prof. Okamura reported on the fabrication and properties of silicon nitride and oxynitride fibers for use in composites.

The highlight of this symposium was the presentation by Dr. $\mathrm{O}^{\prime}$ ishi on the application of advanced composites in advanced railway systems, including the Linear Motor Maglev (LLM), the Automated Linear Motor-Pneumatic tire System (ALPS), and the Speed Up Shinkansen (SUS). Actual examples of composite use were discussed in detail.

\section{Rapid Quenching-B}

Organizers: T. Masumoto (Tohoku University), T. Suzuki (Tokyo University of Agriculture \& Technology), and A. Inoue (Tohoku University).

This exciting symposium highlighted rapid quenching production techniques for new materials and also the structures, properties, and applications for these materials. Topics spanned fundamental and technological aspects of rapid quenching from the melt, solidification phenomena, microstructure and properties of solidified samples, novel applications of quenched products, and related topics in metals, alloys, and ceramics. Nine invited and 21 contributed talks and 32 posters were presented. Invited speakers covered the following topics:

A. Inoue (Tohoku University) presented recent data on the formation, mechanical properties, and thermal stability of new Albased amorphous alloys in metalmetalloid and metal-metal types obtained by melt spinning. He also reported on the mechanical strengths of the amorphous bulks produced by warm consolidation of the amorphous powders. Al-Ni-Y and Al$\mathrm{Ni}$-La amorphous alloys exhibiting tensile strengths above $980 \mathrm{MPa}$ combined with good ductility attracted strong attention.
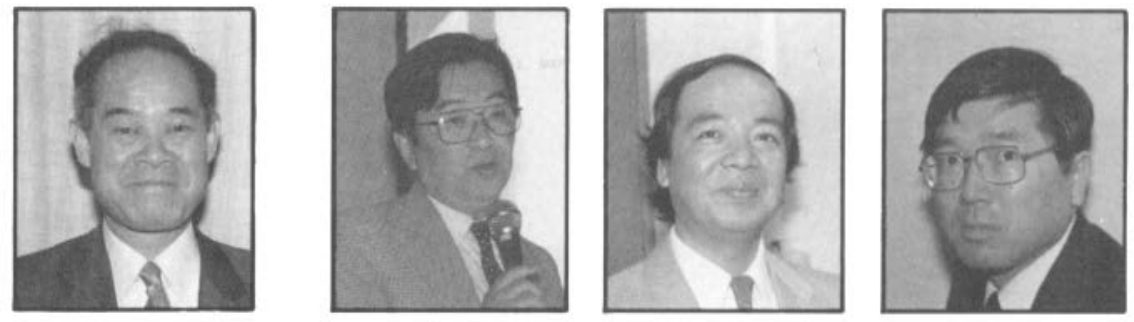

S. Kimura, one of the organizers of Sympo$\operatorname{sium} A$.
Symposium B organizers (left to right): T. Masumoto, T. Suzuki, and A. Inoue. 
H.S. Chen's (AT\&T Bell Laboratories) talk on the stability and growth of quasicrystals focused on stable $\mathrm{Al}-\mathrm{Li}-\mathrm{Cu}$ and $\mathrm{Al}-\mathrm{Cu}-\mathrm{Fe}$ quasicrystals.

T. Sato (Nippon Steel Corporation) described the performance of a stacked core model transformer using an amorphous $\mathrm{Fe}_{80.5} \mathrm{Si}_{65} \mathrm{~B}_{12} \mathrm{C}_{1}$ thick ribbon. Research had shown that even for the thick ribbon (104 $\mu \mathrm{m})$, sufficiently low loss was obtained under optimum annealing conditions. $\mathrm{K}$. Hirao (Kyoto University) reported a marked increase of electrical conductivity for the glasses containing both oxygen and fluoride ions in $\mathrm{MnF}_{2}-\mathrm{MnO}_{2}-\mathrm{SiO}_{2}$ and $\mathrm{MnF}_{2}-$ $\mathrm{PbF}_{2}-\mathrm{SiO}_{2}$ systems. He also explained the mechanism involved.

L. Arnberg (Swedish Institute for Metals Research) reviewed production techniques which give high yields of rapidly solidified powders (particularly high pressure gas atomization) and powder property data for $\mathrm{Fe}$-, $\mathrm{Al}$ - and $\mathrm{Cu}$-based alloys.

L.E. Hackman's (Ribbon Technology Corporation) overview of melt overflow rapid solidification technology focused on applications for as-quenched stainless steel fibers in refractory concrete reinforcement, magnesium alloy sheet for metal matrix composites, and cobalt alloy ribbons for welding filler materials.

E.N. Kaufmann (Lawrence Livermore National Lab) reviewed nucleation and growth behavior of surface layers on Ta-Ir, $\mathrm{Cr}-\mathrm{Ta}$, and $\mathrm{Cu}-\mathrm{Zr}$ alloys after rapid melting by a traveling electron beam. K.V. Rao (Royal Institute of Technology) reviewed physical properties of novel rapidly quenched materials, i.e., amorphous alloys in an extended concentration regime beyond the eutectics, a new class of composite materials where one of the components is an immiscible element, and quasicrystals. S.K. Das (Allied Signal Corporation) described fabrication process, properties, and applications of rapidly quenched Al-Fe-V-Si alloys with superior mechanical properties.

Other major topics in contributed oral and poster presentations spanned the following: preparation of amorphous palladium-based surface alloys by laser and electron beam processing; refractory metal(M)-based amorphous alloys in the $\mathrm{M}_{40} \mathrm{Si}_{10} \mathrm{~B}_{10}$ system with high thermal stability produced by melt spinning; magnetic properties of amorphous ultrafine Fe-B and Co-B powders prepared by sputtering; structural analyses of quasicrystalline alloys in Al-Ge-Mn and Al-Si-Mn transition metal systems; fundamental properties (amorphization mechanism, tensile strength, fatigue strength, corrosion resistance, crystallization kinetics, structural relaxation, and electrical magnetic and superconducting properties) for amorphous alloy and oxide materials in ribbon, powder and wire forms produced by rapid solidification, sputtering, and mechanical alloying; rare earth metal-Ba-Cu oxide superconductors produced by oxidation of either melt-spun alloy ribbons or mechanically alloyed powders; multilayered Al-Mn thin films; microstructure and mechanical, electrical, and magnetic properties of rapidly quenched metastable crystalline alloys in $\mathrm{Al}-, \mathrm{Ti}-, \mathrm{Ni}-, \mathrm{Fe}-, \mathrm{Cu}-$ and $\mathrm{Pb}-$ based systems; and microstructure and solidification mechanism of undercooled $\mathrm{Ni}$-Sn and $\mathrm{Cu}$-Fe alloys.

\section{Joints of Metals and Ceramics-F}

Organizers: N. Iwamoto (Osaka University) and T. Suga (University of Tokyo).

The topic of this symposium touched a problem that is significant in several areas: the construction of fusion reactors, high efficiency heat exchangers, the space shuttle, and biomaterials, to name a few. The symposium focused on structure, filler materials, mechanical properties, and processes for joints of metals and ceramics. The presentations highlighted work in new techniques and revealed new approaches to solve interfacial problems structurally mechanically.

Invited speakers covered the following topics: R.E. Loehman (Sandia National Laboratories) discussed the joining and bonding mechanism in non-oxide ceramics such as $\mathrm{Si}_{3} \mathrm{~N}_{4}, \mathrm{AlN}$, and $\mathrm{SiC}$. M.G. Nicholas (Harwell Laboratory) spoke on reactive brazing of ceramics, particularly noting the role of titanium. He recommended adding some element such as tin to obtain the optimum chemical interaction at the interface. G. Elssner (Max-Planck Institut fuir Metallforschung) reported on the solid state bonding of a ceramic-metal system under ultrahigh vacuum. The nature of the interface was observed with a high resolution transmission electron microscope. Y. Ishida (University of Tokyo) also investigated the structure of the $\mathrm{Al}_{2} \mathrm{O}_{3}-\mathrm{Nb}$ interface by high resolution electron microscopy, emphasizing the effect of impure elements in the original materials. $R$.
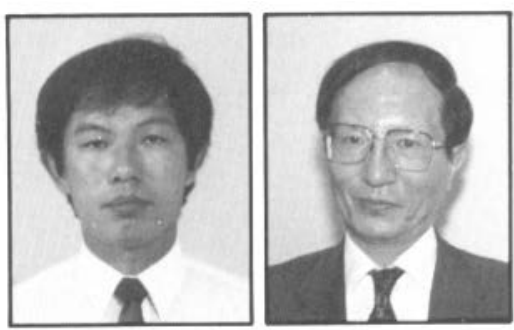

Symposium Forganizers (left to right):

T. Suga and N. Iwamoto.

Yamamoto (University of Tokyo) studied the two-dimensional electronic structures of the interface between the $\mathrm{Al}_{2} \mathrm{O}_{3}$ and $\mathrm{Nb}$ layer using the semi-empirical tightbinding method and the slab model.

F.S. Ohuchi's (Du Pont) presentation centered on new directions to resolve the chemical interactions at metal-ceramic interfaces by combining surface spectroscopies with energy band calculations. Other special bonding techniques (ultrasonic and friction) were discussed. Also reported was the success joining $\mathrm{Si}_{3} \mathrm{~N}_{4}$ by a simple spraying method to make the sialon phase at the interface using components from the $\mathrm{Si}_{3} \mathrm{~N}_{4}-\mathrm{SiO}_{2}-\mathrm{Al}_{2} \mathrm{O}_{3}-\mathrm{Y}_{2} \mathrm{O}_{3}$ system.

Detailed analyses of the interfacial region between $\mathrm{Si}_{3} \mathrm{~N}_{4}$ and $\mathrm{Ni}, \mathrm{Ni}-\mathrm{Cr}$, and $\mathrm{Fe}-\mathrm{Ni}$ were presented. The relationship between joining strengths of $\mathrm{Si}_{3} \mathrm{~N}_{4}$ and $\mathrm{Ni}, \mathrm{Ni}-\mathrm{Cr}$, and $\mathrm{Fe}-\mathrm{Ni}$ were presented. The relationship between joining strength $\mathrm{Si}_{3} \mathrm{~N}_{4}$-metal and the product of $\alpha$ (thermal expansion coefficient of metal species) and $\mathrm{E}$ (elastic constant of metal species) was defined.

Thermal stress from the mismatch of thermal expansion coefficient of metals and ceramics is unavoidable when joining metals and ceramics. Presentations on this topic focused on FEM calculations and using insert metal to minimize thermal stress. The combination of stainless steel/ $\mathrm{Si}_{3} \mathrm{~N}_{4}$, tungsten $/ \mathrm{ZrO}_{2}$, and carbon steel/ $\mathrm{Al}_{2} \mathrm{O}_{3}$ were discussed. Metal implantation and vapor deposition techniques were applied to obtain good interfacial strength between metals and ceramics.

\section{P-MRS \\ 1989 Spring Meeting \\ May 30-June 2, $1989 \square$ Strasbourg, France}

For information contact E-MRS president Paul Siffert at the address listed on page 2 in this issue. 